\title{
The Nexus of Design Thinking and Intrapreneurship: Insights from a large- scale empirical assessment
}

\author{
Carolin Marx \\ Hasso Plattner Institute \\ University of Potsdam \\ carolin.marx@hpi.de
}

\author{
Thomas Haskamp \\ Hasso Plattner Institute \\ University of Potsdam \\ thomas.haskamp@hpi.de
}

\author{
Danielly de Paula \\ Hasso Plattner Institute \\ University of Potsdam \\ danielly.depaula@hpi.de
}

\author{
Falk Uebernickel \\ Hasso Plattner Institute \\ University of Potsdam \\ falk.uebernickel@hpi.de
}

\begin{abstract}
Although the nexus of Design Thinking (DT) and corporate entrepreneurship being heralded as promising, the concrete compositional architecture of how DT manifests in practice has received limited scholarly attention. Drawing on the argument that DT can facilitate intrapreneurial innovation by enabling effective cognition, we developed a multidimensional assessment model that measures DT for intrapreneurial innovation in an organizational context and applied it via an online survey to 547 organizations of different sizes and industries. An analysis of the dimensional and sub-dimensional values obtained from the quantitative survey data in general, and concerning industry and firm size types in detail, enriches our understanding of DT's manifestation in practice. We provide practitioners with a useful tool to assess, benchmark, plan, analyze, and communicate the use of DT for intrapreneurial innovation, and guide future DT and entrepreneurship researchers seeking practitionerrelevant insights with nine propositions derived from our observations.
\end{abstract}

\section{Introduction}

In today's competitive environment, the successful pursuit of growth, strategic renewal, and innovativeness via the exploitation of entrepreneurial opportunities is a common goal of organizations. The use of corporate entrepreneurship, also called intrapreneurship, has attracted growing interest as a means for corporations to enhance the innovative abilities of their employees and, at the same time, increase corporate success by competing, adapting, and performing better in disrupted environments [1]-[4].

However, the creation of corporate entrepreneurship activities is challenging as it involves radically changing internal organizational behavior patterns, which requires ambidexterity [1]. High rates of entrepreneurial project failure are inevitable among firms that practice corporate entrepreneurship [5]. Hence, on a practical level, organizations are in need of guidelines regarding the optimal breeding ground for establishing effective intrapreneurship.

Similar to intrapreneurship, the concept of Design Thinking (DT), described as a novel problem-solving capability with the potential to shape corporate culture [6], growth, and profitability [7], has increasingly received attention from both researchers and practitioners [8], [9]. In support of the relevance of DT for business and management that goes beyond the traditional application to design problems, scholars have shown that DT can be the foundation of competitive advantage [9], [10] and an enabler for an organization's paradigmatic shift in strategic vision [7]. However, although anecdotal reports on the use of DT are abundant, systematic assessments of how organizations use and integrate DT in practice for specific purposes like intrapreneurial innovation are lacking [5].

For this paper, it is argued that both DT and entrepreneurial orientation rely on similar key attributes and principles. The use of DT practices provides ways of managing ambiguity and coping with high uncertainty as is the case in entrepreneurial activities [11]. In the past years, the connection between DT and entrepreneurship has been made in a predominantly educational context [12], [13]. Fewer efforts on the relationship between and the potential integration of the two concepts have been undertaken on the managerial level [14], [15] [11]. On the latter, Klenner et al. [11, p. 34] make a crucial first approach of theoretically integrating DT and effectuation theory in an entrepreneurial context by showing that "Design Thinking can facilitate entrepreneurial innovation and new venture creation as it enables effectual cognition".

Even though recent scholars like Klenner et al. [11, p. 35] provide strong arguments for DT being "conducive for entrepreneurial innovation", and for DT practices being "a catalyst to entrepreneurship", and even propose practical guidelines for enacting the 
cognitive principles that facilitate innovation, a concretization of those DT activities and its current use in practice is still lacking - especially in the context of corporate entrepreneurship. Despite the promising nexus, little empirical research exists that attempts to measure design-based activities for the implementation of intrapreneurial endeavors [14], [15]. We step into this opportunity by posing the following research question:

What is the current state of the integration of Design Thinking activities for intrapreneurial innovation in organizations?

We aim to extend and specify Klenner et al.'s [11] conceptualization by concretizing DT activities for intrapreneurial innovation. For this purpose, we intent to create an assessment model, apply it to organizations to provide insights on the current state of practice, and develop propositions for further testing. Using a large sample size, our aim is to draw a representative picture of organizations' current landscape implementing DT activities for intrapreneurial activities, including organizations from various industries, sizes, and regions. Seeking to concretize the nexus of DT and corporate entrepreneurship, we build a foundation for application-oriented research and offer practitioners a benchmarked assessment tool that is sensitive to contextual factors.

The remainder of this study is organized as follows: First, we present relevant existing work on the nexus of DT and corporate entrepreneurship. An overview of methodology is then followed by the presentation and discussion of the results. We then derive propositions from the results and conclude with a critical reflection and an outlook for future studies.

\section{Related Work}

\subsection{Entrepreneurship}

The field of entrepreneurship has been defined as the "scholarly examination of how, by whom, and with what effects opportunities to create future goods and services are discovered, evaluated, and exploited" [16, p. 218]. Entrepreneurship research distinguishes between studying 1) the sources of opportunities, 2) the process of discovery, evaluation, and exploitation, and 3 ) the set of individuals who discover, evaluate and exploit opportunities [16]. While many different schools of thought have emerged [17], scholars also refer to different forms of entrepreneurship such as intrapreneurship [18] or digital entrepreneurship [19]. While the latter aims to incorporate the impact of digital technology on entrepreneurial outcomes and the process, the former refers to a more mature organizational location in which entrepreneurship takes place internally [18]. In this case, intrapreneurship requires the management of innovation and high uncertainty within an organization [20].

We follow a procedural understanding of entrepreneurship [16] aimed at reflecting on key attributes at the different levels of this process. To sharpen the conceptual distinctiveness of a procedural understanding of entrepreneurship on the firm level, the concept of entrepreneurial orientation has been proposed [21], [22], and defined as the "propensity to act autonomously, innovate, take risks, and act proactively when confronted with market opportunities" [22, p. 257]. When it comes to measurement, key dimensions of entrepreneurial orientation are firm innovativeness, risk-taking ability, and proactiveness [22], [23]. These dimensions are closely related to attributes of DT, which has gained prominence in the business world for its problemsolving and innovation benefits [9].

\subsection{Design Thinking for intrapreneurial innovation}

While a common definition of DT has not yet been agreed upon [9], we follow Nakata and Hwang [24, p. 117], who conceptualized DT as a "design-based approach to solving human problems" that aims to combine viability, feasibility, and desirability. Similar to the concept of entrepreneurship, DT can be understood from a procedural lens with corresponding underlying process attributes [25]. A recent literature review on DT [9] identified ten principal attributes that shape the concept. Key attributes of DT include, among others, human-centeredness and focus on empathy, the interdisciplinary approach to collaboration, and an iterative and experimental approach, which makes DT particularly suitable for uncertain and ambiguous situations [8], [9]. While most of DT's implementations are rooted in product and service design, "the subject matter of design is potentially universal in scope, because design thinking may be applied to any area of human experience" [26, p. 16], [27].

Regarding potential outcomes and benefits, past studies have argued that DT can contribute to an organization's innovation capabilities [28] and may help to shape its culture [6]. Due to these outcomes and effects, DT is often investigated with regards to innovation and entrepreneurial activities in organizations [8], [15], [24], [29], [30].

For example, Sarooghi et al. have provided evidence for the use of DT methodologies to drive entrepreneurship education [13]. Neck and Green argue similarly by stating that entrepreneurs "think and to some extent act like designers" [13, p. 65]. They highlight the alignment between DT and entrepreneurship as a mindset in the way both identify 
and then act upon realizing what could be in response to an opportunity or problem.

Stressing that both entrepreneurs and designers create opportunities for innovation, Garbuio et al. suggest investigating cognitive elements from the design discourse and their effects in entrepreneurial endeavors [12], arguing that "design thinking [...] informs the process and skills needed to spot and develop opportunities" [12, p. 7].

Investigating DT specifically in the context of corporate entrepreneurship, Abrell advocated four key areas of connection [15]. The first topic relates to DT and its ability to help to sense new entrepreneurial opportunities. Second, the notion of dealing with an uncertain environment and the corresponding risks are vital in entrepreneurship research but also vividly reflected in DT and its focus on so-called wicked problems [26]. Thirdly, DT can be intertwined with an organizational corporate entrepreneurship strategy as it is an important element that can foster entrepreneurial thinking. Lastly, entrepreneurial design management is considered promising as it reflects a design-oriented approach to entrepreneurship that is able to offer new perspectives on how to nurture companies' entrepreneurial orientations [15].

Hence, among other integration possibilities, one can see DT as a means of creating new knowledge on corporate entrepreneurial domains. More specifically, the human-centered approach of DT can help to envision meaningful opportunities that are useful for various stakeholders. This shows that DT practices have the potential to bring about effectuation and thereby facilitate innovation in an organizational context [11].

\section{Methodology}

To answer our research question, first we developed a multi-dimensional assessment model for DT-based intrapreneurship grounded in existing literature, then derived items for its operationalization, validated in six expert interviews, and applied the model to 547 organizations involved in intrapreneurial activities via an online survey. In the last step, we derived nine propositions from the observations and iterated them in the course of a DT expert workshop. An overview of the research process is given in Figure 1.

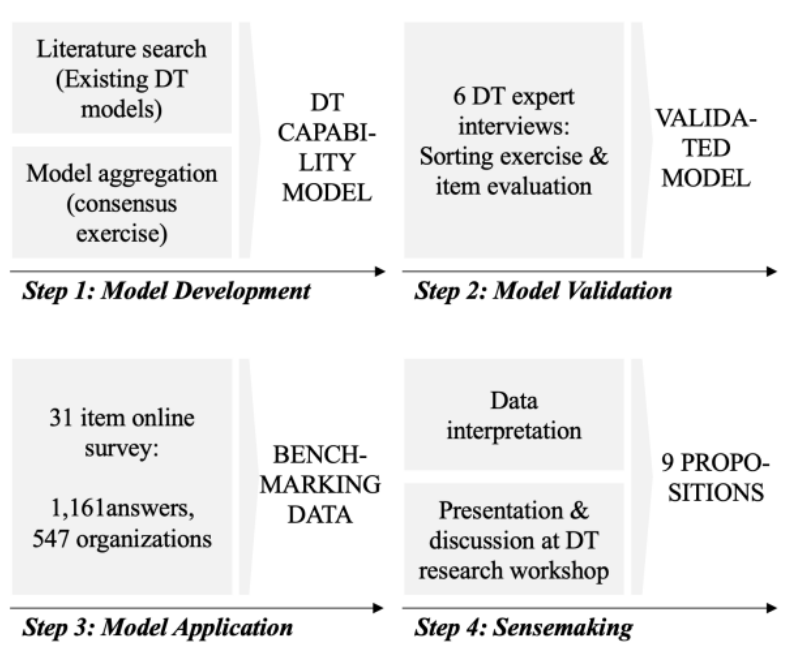

Figure 1. Research Process

\subsection{Model Development}

The survey and the development of the items are based on literature and confirmed by existing interview data [10], [24]. Table 1 shows the corresponding data structure including dimensions and sub-dimensions. Only when all dimensions and subdimensions are combined do they signal a high overall DT capability for intrapreneurship and, as this capability is formed by its dimensions, we define the model as a multidimensional, and multiplicatively aggregated construct. Firm-level DT capabilities for intrapreneurship are formed by DTrelated actions and processes, strategy, organizational resources, and mindset. Each of these dimensions are composed of multiple sub-dimensions, which resulted in a total of 31 items. The final model was developed in an iterative process whereby each author individually aggregated the existing subdimensions [10], [24] which were then discussed and iterated until a consensus was reached. A detailed list of the items and their allocation to the sub-dimensions can be found in Appendix A.

Table 1. Multidimensional structure of the assessment model

\begin{tabular}{|l|l|}
\hline Dimension & Sub-Dimensions \\
\hline $\begin{array}{l}\text { Actions \& } \\
\text { processes (based } \\
\text { on [24]) }\end{array}$ & $\bullet$ Discovery \\
\hline $\begin{array}{l}\text { Strategy (based } \\
\text { on [10]) }\end{array}$ & $\bullet$ Experimentation \\
& $\bullet$ Performance measurement \\
& $\bullet$ Leadership \& decision-making \\
& $\bullet$ Organizational structure
\end{tabular}




\begin{tabular}{|l|l|}
\hline $\begin{array}{l}\text { Organizational } \\
\text { resources (based } \\
\text { on [10]) }\end{array}$ & $\begin{array}{l}\text { • Work environment } \\
\bullet \text { Access to resources } \\
\text { - Learning \& development }\end{array}$ \\
\hline $\begin{array}{l}\text { Mindset (based } \\
\text { on [24]) }\end{array}$ & $\begin{array}{l}\text { - Human-centeredness } \\
\text { - Abductive reasoning } \\
\text { - Learning by failure }\end{array}$ \\
\hline
\end{tabular}

To validate the total set of items, we conducted six semi-structured qualitative interviews with DT experts from academia and practice. All interviewees had more than 5 years of DT experience in an organizational or academic context. The interviews included a subdimension to items sorting exercise and a general assessment of the item's understandability, clarity, and relevance. As a result of this step, we made some minor changes in the wording of the items.

\subsection{Survey Application}

To gather benchmarking data and assess the status quo, the developed model has been applied via an online survey sent to 6,155 practitioners as part of an international massive open online course (MOOC) with the title "Design Thinking in organizations". The course was developed by two of the authors from the Hasso Plattner Institute and targeted practitioners interested in learning how to implement DT in an organizational context. Participation in the survey was introduced as a voluntary activity at the end of the course. Between October and November 2020 1,161 participants participated. Due to the structure and the content of the MOOC, the invited participants were practitioners from various industry fields, departments, regions, and firm sizes with different backgrounds, levels of seniority and experience in DT and corporate entrepreneurship. After aggregating multiple participants from the same organizations and excluding incomplete answers, as well as those from participants not associated with any organization, and those from practitioners working less than 2 years for their organization, the final sample counted 547 organizations. The survey consisted of 31 items on a 5-point rating scale ranging from "strongly disagree" to "strongly agree" based on Nakata and Hwang [24] and Wrigley et al. [10]. Further, we gathered demographic and contextual data like department and job title, industry, firm size (number of employees), and work experience.

As a reliability test, the values of Cronbach's Alpha for the scale are all higher than 0.7. Since the items used were adopted from previous studies, their face validity and content validity are secured.

Using a workshop format with DT experts and researchers from the Hasso Plattner Institute and
Stanford University in the course of a DT-centered academic workshop in March 2021, we presented and discussed our findings to validate the interpretation of the results and the development of our propositions.

\section{Results and Discussion}

The application of the developed assessment model permits a nuanced view of how a variety of organizations is currently using DT for intrapreneurial innovation. In the following, we discuss the findings by dimensions and sub-dimensions, and look at the potential industry and firm-size patterns from which we derive propositions. We utilized data visualization to provide a more in-depth understanding of the different manifestations.

Figure 2 shows the aggregated dimensional scores of DT capabilities for intrapreneurial innovation.

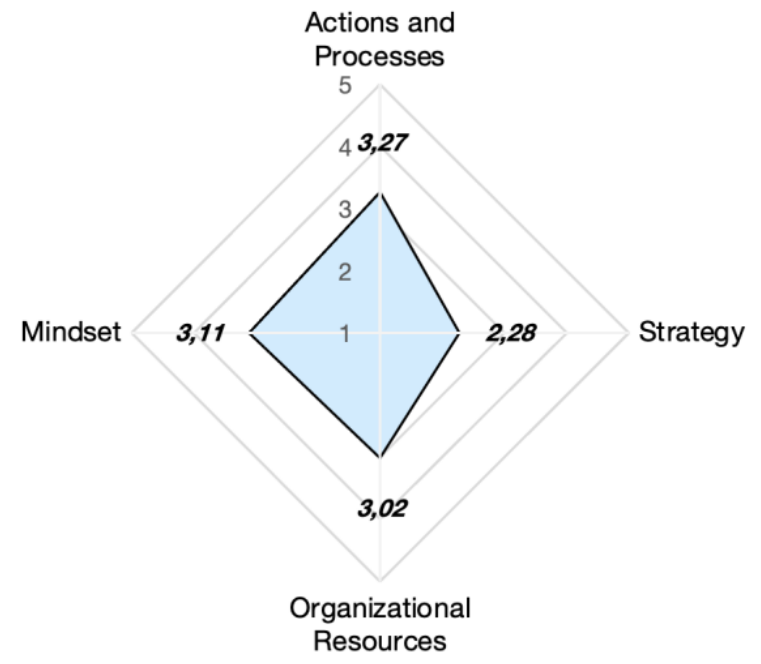

Figure 2. DT capabilities for intrapreneurship dimensional results $(\mathrm{N}=547)$

The results show that overall, aggregated over DTrelated actions and processes, strategy, organizational resources, and mindset, organizations have low DT capabilities for intrapreneurial innovation $(\mathrm{M}=2.92$, $\mathrm{SD}=0.44)$. This indicates that the full potential of how organizations can use and integrate DT for intrapreneurial innovation is not yet fully exploited.

In particular, the integration of DT on a strategic level is low $(\mathrm{M}=2.28, \mathrm{SD}=0.89)$, while we found the highest scores in the area of actions and processes $(\mathrm{M}=3.27 ; \mathrm{SD}=0.86)$. This is interesting as it gives a comparative glimpse into the manifestation of DT for intrapreneurship and indicates stages of integration. A potential explanation for the limited integration of DT on a strategic level could be the challenging nature of 
frequently changing organizational structures and topmanagement decision-making patterns, while concrete actions like ideation processes are easier to implement in a corporate setting.

Linking our findings back to the presented literature, we can see that the heralded paradigm shift from DT's product-centered to a more holistic use within organizations [26], [27] is not manifested in practice yet. Moreover, the findings confirm that intrapreneurial innovation activities with the use of DT are challenging [1] and, by looking at the dimensional inter-organizational variance (Appendix B), differ significantly between firms. The identified low strategic integration of DT capabilities for intrapreneurship across all firms indicates a potential systematic barrier. We therefore develop the following propositions regarding the overall use of DT for intrapreneurship:

\section{P.1. The main barrier for organizations to exploit} the potential of Design Thinking for intrapreneurial innovation is lack of strategic integration.

P.2. Organizations start incorporating Design Thinking for intrapreneurial innovation via actions and processes and a Design Thinking mindset, then secure and build organizational resources, and only lastly incorporate it into their organizational strategy.

When looking at the results in more detail, on a subdimensional level, as presented in Figure 3, we can get more insights on the manifestation within the dimensions.

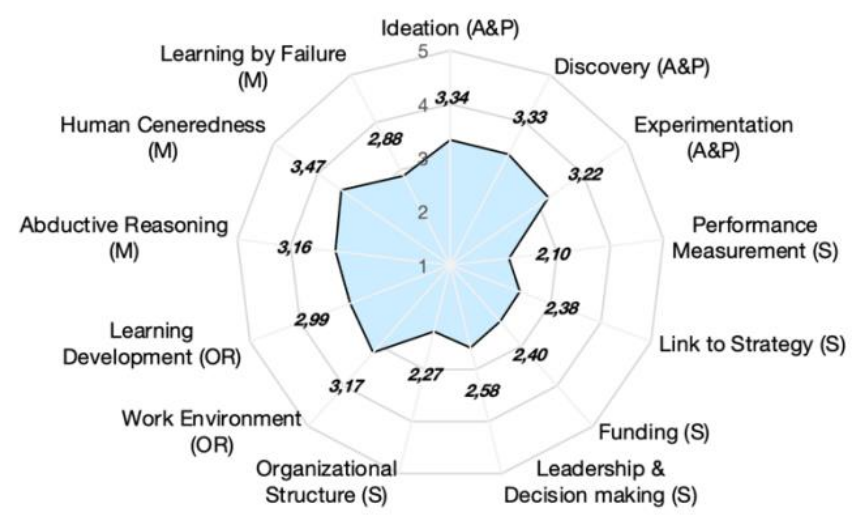

Figure 3. DT capabilities for intrapreneurship -
sub-dimensional results $(\mathrm{N}=547)$

The sub-dimensional analysis shows that the weak integration of DT on a strategic level can be traced back to particularly low levels in organizational structure $(M=2.27 ; \quad S D=1.05)$, linkage to strategy $(M=2.38$;
$\mathrm{SD}=1.04)$, and performance measurement $(\mathrm{M}=2.10$; $\mathrm{SD}=1.06)$. One can derive that clear roles and responsibilities, as part of an organizational structure for DT-related activities, are generally lacking and that only a few firms incorporate DT throughout their whole organization as a central pillar of corporate strategy. Further, the results indicate that the performance measurement of DT activities for intrapreneurial innovation remains a central challenge, as it received the lowest scores in our dataset. Another factor accounting for the weak integration of DT on a strategic level is the lack of sufficient funding for DT activities $(\mathrm{M}=2.40$; $\mathrm{SD}=1.09$ ).

The observation about performance measurement and the neglect of clear roles and responsibilities as part of an organizational structure is in line with previous studies on the challenges of performance measurement of innovation activities [29].

Another observation from the sub-dimensional data is that within the dimensions of a DT mindset, including human-centeredness, abductive reasoning, and learning by failure, the latter is mentioned less often as being integrated into the overall corporate mindset $(\mathrm{M}=2.88$, $\mathrm{SD}=0.98)$. This is surprising as we purposefully included organizations from various countries in our sample to account for potential cultural differences. The results suggest that inviting mistakes to learn from is generally a challenge for organizations.

On the other hand, when looking at where firms from our sample are most mature regarding the integration of DT for intrapreneurial innovation we find ideation $(\mathrm{M}=3.34 ; \mathrm{SD}=0.94)$, discovery $(\mathrm{M}=3.33$, $\mathrm{SD}=0.98)$, and experimentation $(\mathrm{M}=3.22, \mathrm{SD}=0.89)$ as part of concrete DT actions and processes with the highest levels. Here, ideation processes are integrated most extensively within organizations. Another area where firms of our sample deeply integrate DT is the work environment $(\mathrm{M}=3.17, \mathrm{SD}=0.93)$ as part of organizational resources. An example is physical spaces dedicated to being used for DT-related activities.

In general, when looking at the variance (Appendix B), we can also observe significant inter-organizational differences on the sub-dimensional level.

Hence, based on the sub-dimensional findings and their interpretation, we derive the following propositions:

P.3. Organizations struggle with integrating Design Thinking for intrapreneurial innovation due to challenges arising from (the lack of) performance measurement and (changing) organizational structure.

P.4. Organizations from across cultures struggle with integrating learning from failure into their organizational mindset. 


\subsection{Industry patterns}

When looking at industry patterns on an aggregated level, the results indicate differences between the average DT integration for intrapreneurial innovation in different types of industry. An ANOVA conducted on the collected data confirms significant differences in the overall scores between the different industries $[\mathrm{F}(4$, $276)=4.90, \mathrm{p}=0.001]$. Details of a post-hoc comparison can be accessed in Appendix C.

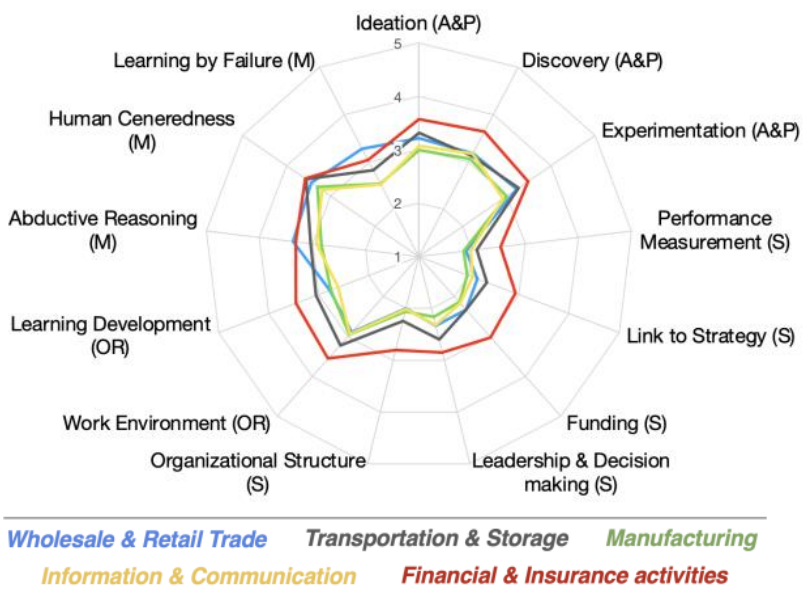

Figure 4. DT capabilities for intrapreneurship sub-dimensional results by industry $(\mathrm{N}=281)$

The detailed, sub-dimensional view as shown in Figure 4 gives more insights into where differences are rooted in. One can see that companies in the financial and insurance industry have the highest aggregated levels of DT integration $(\mathrm{M}=3.22, \mathrm{SD}=0.37)$ which is visible in all sub-dimensions except for learning by failure and abductive reasoning as part of a DT mindset.

On the other hand, for organizations from the manufacturing $(\mathrm{M}=2.59, \mathrm{SD}=0.49)$ and information and communication sectors $(\mathrm{M}=2.61, \mathrm{SD}=0.46)$ we can report the lowest DT integration levels compared to other industries. This is especially the case in the performance measurement sub-dimension.

In general, the industry differences show that the manifestation of DT actions and processes, strategy, mindset, and organizational resources are not of the same relevance across different industries, or are differently challenging. Hence, our findings support calls for more targeted integration strategies [10]. From our industry-specific observations, we can derive the following propositions:

P.5. The challenges and success factors of integrating Design Thinking for intrapreneurial innovation depend on the industry as a contextual factor.

P.6. Traditional industries like the manufacturing industry encounter more barriers in using Design Thinking for intrapreneurial innovation than those located in fast-changing environments, like the financial and insurance industries.

\subsection{Firm-Size patterns}

Regarding firm-size patterns on an aggregated level, the results indicate differences between the average DT integration for intrapreneurial innovation of the different groups based on firm size. An ANOVA conducted on the collected data confirms significant differences in the dimensional scores between firm size groups $[\mathrm{F}(4,542)=12.64, \mathrm{p}<0.001]$. Details of a posthoc comparison can be accessed in Appendix C.

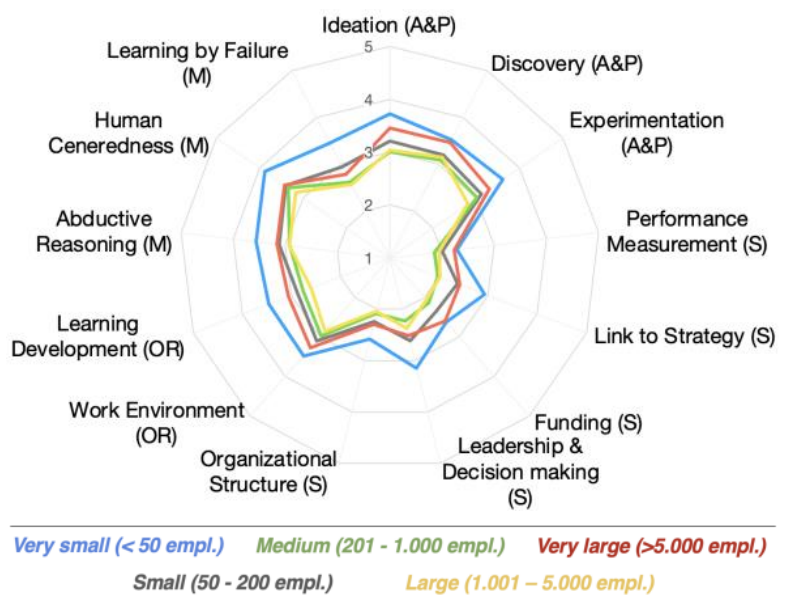

Figure 5. DT capabilities for intrapreneurship sub-dimensional results by firm size $(\mathrm{N}=547)$

A key observation derived from the data is that very small organizations (less than 50 employees) account for the highest overall DT integration for intrapreneurial innovation $(\mathrm{M}=3.25, \mathrm{SD}=0.50)$. Potential explanations could be the relatively small effort necessary to integrate DT up to a strategic level and more dynamic organizational structures.

We can find the biggest gap between small (50 to 200 employees) and large organizations (more than 1000 , but less than 5001 employees) in the areas of leadership and decision-making (small: $\mathrm{M}=2.61$, $\mathrm{SD}=0.99$; large: $\mathrm{M}=2.37, \mathrm{SD}=0.91$ ) and link to strategy (small: $\mathrm{M}=2.38, \mathrm{SD}=1.00$; large: $\mathrm{M}=2.02, \mathrm{SD}=0.82$ ). Here, an explanation could be that small firms are more 
likely to anchor DT directly on the level of strategic and top management decision-making.

These findings are in line with arguments for more context-sensitive integration strategies [10]. Further, they suggest looking at very small organizations' DT integration strategies for larger organizations to adapt and learn from. Hence, we developed the following propositions based on our specific firm-size observations:

P.7. The challenges and success factors of integrating Design Thinking for intrapreneurial innovation depend on firm size as a contextual factor.

P.8. Very small organizations (less than 50 employees) integrate Design Thinking for intrapreneurial innovation more deeply within their organizational structure, strategy, actions and processes, and mindset due to less effort required to change their established structures.

P.9. Very small organizations (less than 50 employees) integrate Design Thinking for intrapreneurial innovation more deeply within their organizational structure, strategy, actions and processes, and mindset because they are more likely to directly anchor Design Thinking on a strategic level.

\section{Conclusion}

Although the nexus of DT and corporate entrepreneurship being heralded as promising, the concrete compositional architecture of how DT manifests in practice has not yet been examined. Drawing on the argument that DT can facilitate intrapreneurial innovation as it enables effectual cognition, we developed and applied a multidimensional assessment model that measures DT for intrapreneurial innovation in an organizational context and derived propositions.

We enriched the understanding of DT's manifestation in practice by analyzing the dimensional and sub-dimensional values obtained from the quantitative survey data in general, and with regard to industry and firm size types, more specifically. The visual display of the results in the form of radar charts enables a more nuanced comparison and interpretation of the data. The analysis shows that significant differences between industries and firm sizes exist and draws a representative and detailed picture of the current organizational landscape. Further, the generated propositions can be transformed into hypotheses for further investigations.

\subsection{Academic implementations and future research}

Our findings provide new insights into how DT manifests in practice and thereby allow to create new knowledge in corporate entrepreneurial domains. We make several academic contributions:

Firstly, the developed multidimensional assessment model serves as a concretization and operationalization of DT in an intrapreneurial context that has been criticized to be vague and lacking empirical evidence. The high inter-organizational variance we identified in the dimensional and sub-dimensional DT capabilities (Appendix B) indicates sufficient heterogeneity and enables future studies to investigate the antecedents, effects, moderators, and mediators of DT for corporate entrepreneurship using the presented model. Similarly, the model can be utilized for inter-organizational comparisons to be made over several points in time in the course of longitudinal studies. We encourage future researchers investigating DT's relation with other variables, like potential organizational outcomes, to not understand DT as a dichotomous construct, but to view and assess it as multidimensional and formative. This allows for a more nuanced, realistic understanding and could explain different effects on outcome variables from organizations that overall have the same DT capability level.

Secondly, the large-scale application of the model to over 500 organizations from various industries and regions permits valuable insights to be derived on the current state of practice. The analyzed patterns and proposed interpretations presented as inductively generated propositions can be turned into hypotheses for further quantitative testing. It would be interesting, for instance, to identify industry-specific characteristics that could account for the differences, or to investigate firm size as a potential moderating factor on the performance effects of DT capabilities for corporate entrepreneurship.

Thirdly, the present study adds to corporate entrepreneurship literature by providing insights on how DT is used in practice to foster intrapreneurial success.

Fourthly, the study adds to the current innovation literature by showing the concrete manifestation of DT in corporate entrepreneurship. We thereby add to the paradigm shift of DT from its form-giving and productcentered origins towards an ecosystem-centered and integrated use of DT.

\subsection{Managerial implementations}

The developed multidimensional model can serve as a self-assessment tool for practitioners working in corporate entrepreneurship settings who are interested 
in the success of their organization's DT efforts. Additional to the model, we provide practitioners with industry- and firm size-specific benchmarking data as guidance for interpreting the results.

Our assessment can stimulate discussions across silos, roles, and seniority levels, and increases the awareness of DT's current manifestation and use for intrapreneurial means within an organization. Knowing the current state of DT integration for intrapreneurship on a dimensional and sub-dimensional level can support the communication of current or targeted corporate entrepreneurship strategies and help to identify areas for improvement.

These insights allow intrapreneurs and managers to make more informed decisions regarding the planning, implementation, and evaluation of DT efforts for successful intrapreneurial innovation.

\subsection{Limitations}

Regarding limitations, we are aware of the convenience sampling used via the online course which accessed practitioners from various industries and seniority levels. Even though this permits a large-scale application, the estimates derived from convenience samples are often biased [31].

Further, we intentionally designed the assessment model to be formative and multiplicative by nature so that an overall high level can only be achieved with sufficiently high levels across all dimensions and subdimensions. However, this implies equal importance accorded to all four dimensions. With future variance studies investigating the relationship between the overall capability levels, dimensional and subdimensional scores, and outcome variables such as financial performance, we can achieve a better understanding of potential effect differences between the dimensions and include weight adjustments in the model.

Moreover, the low conceptual maturity of DT [9] might limit the construct validity and can account for potential overlaps between our dimensions. To account for this limitation, future studies could include additional data sources measuring DT for triangulation.

\section{References}

[1] D. F. Kuratko, R. V. Montagno, and J. S. Hornsby, "Developing an Intrapreneurial Assessment Instrument for an Effective Corporate Entrepreneurial Environment," Strategic Management Journal, vol. 11, pp. 49-58, 1990.

[2] D. Skarmeas, A. Lisboa, and C. Saridakis, "Export performance as a function of market learning capabilities and intrapreneurship: SEM and FsQCA findings," J. Bus. Res., vol. 69, no. 11, pp. 5342-5347, Nov. 2016.

[3] A. M. Olokundun, H. O. Falola, A. S. Ibidunni, O. O. Ogunnaike, F. Peter, and O. J. Kehinde,

"Intrapreneurship and Innovation Performance: A conceptual," Academy of Strategic Management Journal, vol. 17, no. 2, 2017, Accessed: Jun. 15, 2021.

[4] C. Heavey and Z. Simsek, "Top management compositional effects on corporate entrepreneurship: The moderating role of perceived technological uncertainty," J. Prod. Innov. Manage., vol. 30, no. 5, pp. 837-855, Sep. 2013.

[5] D. A. Shepherd, J. G. Covin, and D. F. Kuratko, "Project failure from corporate entrepreneurship: Managing the grief process," J. Bus. Venturing, vol. 24, no. 6, pp. 588-600, Nov. 2009.

[6] K. D. Elsbach and I. Stigliani, "Design Thinking and Organizational Culture: A Review and Framework for Future Research," J. Manage., vol. 44, no. 6, pp. 2274 2306, Jul. 2018.

[7] H. Collins, "Can design thinking still add value?," Des. Manage. Rev., vol. 24, no. 2, pp. 35-39, Jun. 2013.

[8] J. Liedtka, "Perspective: Linking Design Thinking with Innovation Outcomes through Cognitive Bias Reduction," Journal of Product Innovation Management, vol. 32, no. 6, pp. 925-938, Nov. 2015.

[9] P. Micheli, S. J. S. Wilner, S. H. Bhatti, M. Mura, and M. B. Beverland, "Doing Design Thinking: Conceptual Review, Synthesis, and Research Agenda," J Prod Innov Manag, vol. 36, no. 2, pp. 124-148, Mar. 2019.

[10] C. Wrigley, E. Nusem, and K. Straker, "Implementing Design Thinking: Understanding Organizational Conditions," Calif. Manage. Rev., vol. 62, no. 2, pp. 125-143, Feb. 2020.

[11] N. F. Klenner, G. Gemser, and I. O. Karpen, "Entrepreneurial ways of designing and designerly ways of entrepreneuring: Exploring the relationship between design thinking and effectuation theory," J. Prod. Innov. Manage., no. jpim.12587, Jun. 2021.

[12] M. Garbuio, A. Dong, N. Lin, T. Tschang, and D. Lovallo, "Demystifying the Genius of Entrepreneurship: How Design Cognition Can Help Create the Next Generation of Entrepreneurs," AMLE, vol. 17, no. 1, pp. 41-61, Mar. 2018.

[13] H. Sarooghi, S. Sunny, J. Hornsby, and S. Fernhaber, "Design thinking and entrepreneurship education: Where are we, and what are the possibilities?," J. Small Bus. Manage., vol. 57, no. S1, pp. 78-93, Jul. 2019.

[14] M. G. Goldsby, D. F. Kuratko, M. R. Marvel, and T. Nelson, "Design-Centered Entrepreneurship: A Four Stage Iterative Process for Opportunity Development," Int. J. Entrep. Small Bus., vol. 29, no. 6, pp. 477-490, Nov. 2017.

[15] T. Abrell, "Design Thinking and Corporate Entrepreneurship: An Integration and Avenues for Future Research," in Design Thinking for Innovation: Research and Practice, W. Brenner and F. Uebernickel, Eds. Cham: Springer International Publishing, 2016, pp. 25-39.

[16] S. Shane and S. Venkataraman, "The promise of 
entrepreneurship as a field of research," Acad. Manage. Rev., vol. 25, no. 1, pp. 217-226, Jan. 2000.

[17] S. Shane, "Prior Knowledge and the Discovery of Entrepreneurial Opportunities," Organization Science, vol. 11 , no. 4, pp. 448-469, Aug. 2000.

[18] W. D. Guth and A. Ginsberg, "Guest Editors' Introduction: Corporate Entrepreneurship," Strategic Management Journal, vol. 11, pp. 5-15, 1990.

[19] S. Nambisan, "Digital Entrepreneurship: Toward a Digital Technology Perspective of Entrepreneurship," Entrepreneurship Theory and Practice, vol. 41, no. 6, pp. 1029-1055, Nov. 2017.

[20] C. Bandera, F. Keshtkar, M. R. Bartolacci, S. Neerudu, and K. Passerini, "Knowledge management and the entrepreneur: Insights from Ikujiro Nonaka's Dynamic Knowledge Creation model (SECI)," International Journal of Innovation Studies, vol. 1, no. 3, pp. 163174, Dec. 2017.

[21] G. T. Lumpkin and G. G. Dess, "Clarifying the Entrepreneurial Orientation Construct and Linking It To Performance," AMRO, vol. 21, no. 1, pp. 135-172, Jan. 1996.

[22] O. C. Richard, T. Barnett, S. Dwyer, and K. Chadwick, "Cultural Diversity in Management, Firm Performance, and the Moderating Role of Entrepreneurial Orientation Dimensions," Academy of Management Journal, vol. 47, no. 2. pp. 255-266, 2004, doi: 10.5465/20159576.

[23] G. T. Lumpkin, B. Erdogan, and Others, "If not entrepreneurship, can psychological characteristics predict entrepreneurial orientation? A pilot study," The ICFAI Journal of Entrepreneurship Development, vol. 1, no. 1, pp. 21-33, 2004.

[24] C. Nakata and J. Hwang, "Design thinking for innovation: Composition, consequence, and contingency," J. Bus. Res., vol. 118, pp. 117-128, Sep. 2020.

[25] W. Brenner, F. Uebernickel, and T. Abrell, "Design Thinking as Mindset, Process, and Toolbox," in Design Thinking for Innovation, 2016, pp. 3-21.

[26] R. Buchanan, "Wicked Problems in Design Thinking," Design Issues, vol. 8, no. 2, pp. 5-21, 1992.

[27] U. Johansson-Sköldberg and J. Woodilla, "Design thinking: past, present and possible futures," Creativity and Innovation Management, vol. 22, pp. 121-146, June 2013.

[28] L. Carlgren, M. Elmquist, and I. Rauth, "Design Thinking: Exploring Values and Effects from an Innovation Capability Perspective," The Design Journal, vol. 17, no. 3, pp. 403-423, Sep. 2014.

[29] S. Mayer, T. Haskamp, and D. de Paula, "Measuring what Counts: An Exploratory Study about the Key Challenges of Measuring Design Thinking Activities in Digital Innovation Units," in Proceedings of the 54th Hawaii International Conference on System Sciences, Virtual, Dec. 2020, pp. 4951-4960.

[30] C. Marx, D. de Paula, T. Haskamp, and F. Uebernickel, "Design Thinking Diffusion Model: Empirical insights into the status quo," presented at the The ISPIM Innovation Conference -Innovating Our Common Future, Berlin, Germany, 2021.

[31] I. Etikan, S. A. Musa, and R. S. Alkassim, "Comparison of convenience sampling and purposive sampling," American journal of theoretical and applied statistics, vol. 5, no. 1, pp. 1-4, 2016. 


\section{Appendix A}

\section{Detailed data structure}

\begin{tabular}{|c|c|c|}
\hline $\begin{array}{l}\text { Dimen- } \\
\text { sion }\end{array}$ & $\begin{array}{l}\text { Sub- } \\
\text { Dimension }\end{array}$ & Items \\
\hline \multirow[t]{3}{*}{$\begin{array}{l}\text { Actions } \\
\& \text { pro- } \\
\text { cesses }\end{array}$} & Discovery & $\begin{array}{l}\text { - In our organization, we collect } \\
\text { first-hand data on customers to } \\
\text { discover deep needs } \\
\text { - In our organization, we seek to } \\
\text { discover new insights on } \\
\text { customers through research } \\
\text { - In our organization, we utilize } \\
\text { various methods to make fresh } \\
\text { discoveries about customers }\end{array}$ \\
\hline & Ideation & $\begin{array}{l}\text { - In our organization, we generate } \\
\text { new concepts that challenge } \\
\text { what's assumed to work } \\
\text { - In our organization, we } \\
\text { brainstorm new concepts to } \\
\text { meet customers' functional and } \\
\text { emotional wants } \\
\text { - In our organization, we arrive at } \\
\text { fundamentally new concepts by } \\
\text { reframing problems } \\
\text { - In our organization, we ask } \\
\text { questions to ideate new concepts }\end{array}$ \\
\hline & $\begin{array}{l}\text { Experimen- } \\
\text { tation }\end{array}$ & $\begin{array}{l}\text { - In our organization, we } \\
\text { iteratively test ideas to refine } \\
\text { and launch new products or } \\
\text { services } \\
\text { - In our organization, we } \\
\text { repeatedly experimenting while } \\
\text { developing new products or } \\
\text { services } \\
\text { - In our organization, we adjust } \\
\text { new product or service ideas } \\
\text { more than once based on } \\
\text { customer feedback }\end{array}$ \\
\hline \multirow[t]{4}{*}{$\begin{array}{l}\text { Strate- } \\
\text { gy }\end{array}$} & $\begin{array}{l}\text { Perfor- } \\
\text { mance } \\
\text { measure- } \\
\text { ment }\end{array}$ & $\begin{array}{l}\text { - A measurement system is in } \\
\text { place to steer and monitor } \\
\text { Design Thinking activities }\end{array}$ \\
\hline & Funding & $\begin{array}{l}\text { - Design Thinking initiatives are } \\
\text { sufficiently funded }\end{array}$ \\
\hline & $\begin{array}{l}\text { Leadership } \\
\text { and } \\
\text { Decision } \\
\text { Making }\end{array}$ & $\begin{array}{l}\text { - Design Thinking drives our } \\
\text { managerial decision making } \\
\text { - Management supports \& } \\
\text { encourages Design Thinking } \\
\text { initiatives throughout the } \\
\text { organization }\end{array}$ \\
\hline & Link to & - Design Thinking initiatives are \\
\hline
\end{tabular}

\begin{tabular}{|c|c|c|}
\hline & Strategy & $\begin{array}{l}\text { incorporated in our business } \\
\text { strategy } \\
\text { - Design Thinking is effectively } \\
\text { integrated throughout the } \\
\text { organization }\end{array}$ \\
\hline & $\begin{array}{l}\text { Organiza- } \\
\text { tional } \\
\text { Structure }\end{array}$ & $\begin{array}{l}\text { - The mindset of DT is displayed } \\
\text { in clear roles and } \\
\text { responsibilities }\end{array}$ \\
\hline \multirow{3}{*}{$\begin{array}{l}\text { Organi- } \\
\text { zational } \\
\text { Resour- } \\
\text { ces }\end{array}$} & $\begin{array}{l}\text { Work } \\
\text { Environ- } \\
\text { ment }\end{array}$ & $\begin{array}{l}\text { - Our work environment (e.g., } \\
\text { physical spaces) fosters the } \\
\text { application of Design Thinking }\end{array}$ \\
\hline & $\begin{array}{l}\text { Access to } \\
\text { Resources }\end{array}$ & $\begin{array}{l}\text { - Access to organizational } \\
\text { resources is continuously } \\
\text { provided (clients, manufacturing } \\
\text { opportunities) }\end{array}$ \\
\hline & $\begin{array}{l}\text { Learning } \\
\text { Develop- } \\
\text { ment }\end{array}$ & $\begin{array}{l}\text { Within our organization } \\
\text { everyone has the opportunity to } \\
\text { build \& further develop Design } \\
\text { Thinking skills }\end{array}$ \\
\hline \multirow[t]{3}{*}{ Mindset } & $\begin{array}{l}\text { Human- } \\
\text { Centered- } \\
\text { ness }\end{array}$ & $\begin{array}{l}\text { - In our organization, we } \\
\text { empathize deeply with } \\
\text { customers } \\
\text { - In our organization, we are more } \\
\text { centered on customer, not } \\
\text { business', needs } \\
\text { - In our organization, we maintain } \\
\text { the human perspective while } \\
\text { solving customer problems }\end{array}$ \\
\hline & $\begin{array}{l}\text { Abductive } \\
\text { Reasoning }\end{array}$ & $\begin{array}{l}\text { - In our organization, we push the } \\
\text { boundaries of possible product } \\
\text { or service ideas } \\
\text { - In our organization, we go } \\
\text { beyond immediately observable } \\
\text { solutions } \\
\text { - In our organization, we ask } \\
\text { "what if" questions to discover } \\
\text { new ideas } \\
\text { - In our organization, we } \\
\text { challenge "what is" or assumed } \\
\text { in pursuit of novelty }\end{array}$ \\
\hline & $\begin{array}{l}\text { Learning } \\
\text { by failure }\end{array}$ & $\begin{array}{l}\text { - In our organization, we invite } \\
\text { mistakes in order to learn } \\
\text { - In our organization, we embrace } \\
\text { failures because they lead to } \\
\text { new insights } \\
\text { - In our organization, we risk } \\
\text { failure early and often } \\
\text { - In our organization, we believe } \\
\text { better solutions come faster by } \\
\text { permitting failure }\end{array}$ \\
\hline
\end{tabular}




\section{Appendix B}

Variance table of dimensional values $n=547$; Range: 1 (lowest) - 5 (highest)

\begin{tabular}{|l|l|l|}
\hline Dimension & Mean & SD \\
\hline Actions \& processes & 3.27 & 0.86 \\
\hline Strategy & 2.28 & 0.89 \\
\hline Organizational resources & 3.02 & 0.97 \\
\hline Mindset & 3.11 & 0.84 \\
\hline
\end{tabular}

Variance table of sub-dimensional values $n=547$; Range: 1 (lowest) -5 (highest)

\begin{tabular}{|l|l|l|}
\hline Sub-Dimension & Mean & SD \\
\hline Ideation & 3.34 & 0.94 \\
\hline Discovery & 3.33 & 0.99 \\
\hline Experimentation & 3.22 & 0.89 \\
\hline Performance Measurement & 2.10 & 1.06 \\
\hline Link to Strategy & 2.38 & 1.04 \\
\hline Funding & 2.40 & 1.09 \\
\hline Leadership \& Decision-Making & 2.58 & 1.05 \\
\hline Organizational Structure & 2.27 & 1.05 \\
\hline Work Environment & 3.17 & 0.93 \\
\hline Learning Development & 2.99 & 1.20 \\
\hline Abductive Reasoning & 3.16 & 0.90 \\
\hline Human Centeredness & 3.47 & 0.89 \\
\hline Learning by Failure & 2.88 & 0.98 \\
\hline
\end{tabular}




\section{Appendix C}

ANOVA \& Post hoc comparison (Tukey's HSD) Firm size differences

\begin{tabular}{rrrrr} 
& sum_sq & df & F & PR(>F) \\
\hline size & 30.096109 & 4.0 & 12.644424 & $7.627710 \mathrm{e}-10$ \\
Residual & 322.515490 & 542.0 & $\mathrm{NaN}$ & $\mathrm{NaN}$
\end{tabular}

\begin{tabular}{|c|c|c|c|c|c|c|c|}
\hline coup1 & & roup2 & diff & p-adj & lower & upper & reject \\
\hline large & & medium & 0.0339 & 0.9 & -0.286 & 0.3538 & False \\
\hline large & & small & 0.2355 & 0.3185 & -0.1037 & 0.5747 & False \\
\hline large & very & y large & 0.3105 & 0.0283 & 0.0212 & 0.5998 & True \\
\hline large & very & y small & 0.6768 & 0.001 & 0.3631 & 0.9906 & True \\
\hline medium & & small & 0.2016 & 0.4097 & -0.1149 & 0.518 & False \\
\hline medium & very & y large & 0.2766 & 0.0328 & 0.0144 & 0.5388 & True \\
\hline medium & very & y small & 0.6429 & 0.001 & 0.354 & 0.9319 & True \\
\hline small & very & y large & 0.075 & 0.9 & -0.2104 & 0.3605 & False \\
\hline small & very & y small & 0.4414 & 0.001 & 0.1312 & 0.7516 & True \\
\hline large & very & y small & 0.3663 & 0.001 & 0.1117 & 0.621 & True \\
\hline
\end{tabular}

\section{ANOVA \& Post hoc comparison (Tukey's HSD)} Industry differences

\begin{tabular}{rrrrr} 
& sum_sq & df & F & PR(>F) \\
\hline industry & 11.190968 & 4.0 & 4.895313 & 0.000791 \\
Residual & 157.737983 & 276.0 & $\mathrm{NaN}$ & $\mathrm{NaN}$
\end{tabular}

Multiple Comparison of Means - Tukey HSD, FWER=0.05

\begin{tabular}{|c|c|c|c|c|c|c|}
\hline group1 & group2 & meandiff & $\mathrm{p}-\mathrm{adj}$ & lower & upper & reject \\
\hline Financial a. Insurance & Information a. communication & 0.4104 & 0.0142 & 0.0557 & 0.7652 & True \\
\hline Financial a. Insurance & Manufacturing & 0.0752 & 0.9 & -0.3178 & 0.4681 & False \\
\hline Financial a. Insurance & Transportation a. storage & 0.091 & 0.9 & -0.4557 & 0.6377 & False \\
\hline Financial a. Insurance & Wholesale a. retail trade & -0.2835 & 0.8214 & -1.0401 & 0.4732 & False \\
\hline Information a. communication & Manufacturing & -0.3353 & 0.0229 & -0.64 & -0.0306 & True \\
\hline Information a. communication & Transportation a. storage & -0.3194 & 0.3764 & -0.8067 & 0.1678 & False \\
\hline Information a. communication & Wholesale a. retail trade & -0.6939 & 0.0619 & -1.4087 & 0.0209 & False \\
\hline Manufacturing & Transportation a. storage & 0.0158 & 0.9 & -0.4998 & 0.5315 & False \\
\hline Manufacturing & Wholesale a. retail trade & -0.3586 & 0.645 & -1.0931 & 0.3759 & False \\
\hline Transportation a. storage & Wholesale a. retail trade & -0.3745 & 0.7001 & -1.2015 & 0.4526 & False \\
\hline
\end{tabular}

